\title{
GASTRIC VOLVULUS: A Case Report and Literature Review
}

\author{
D. M. Seto ${ }^{1}$, S. G. R. Attolou ${ }^{2}$, M. G. Yassegoungbe ${ }^{3}$, \\ K. M. Savi de Tove ${ }^{4}$, S. A. Allode ${ }^{1}$
}

${ }^{1}$ General Surgery, Parakou's University Hospital Center, Parakou, Benin

${ }^{2}$ Visceral Surgery, HKM National University Hospital Center, Cotonou, Benin

${ }^{3}$ Pediatric surgery, HKM National University Hospital Center, Cotonou, Benin

${ }^{4}$ Radiology Department, Parakou's University Hospital Center, Parakou, Benin

Email: *seto.morel@gmail.com

How to cite this paper: Seto, D.M., Attolou, S.G.R., Yassegoungbe, M.G., de Tove, K.M.S. and Allode, S.A. (2020) GASTRIC VOLVULUS: A Case Report and Literature Review. Surgical Science, 11, 122-126. https://doi.org/10.4236/ss.2020.116016

Received: May 16, 2020

Accepted: June 14, 2020

Published: June 17, 2020

Copyright (C) 2020 by author(s) and Scientific Research Publishing Inc. This work is licensed under the Creative Commons Attribution International License (CC BY 4.0). http://creativecommons.org/licenses/by/4.0/

\begin{abstract}
Background: Gastric volvulus is a rare surgical emergency that causes an upper digestive obstruction due to a rotation of the stomach greater than $180^{\circ}$. Observation: We report the case of a 2-year-old patient referred from a health care facility for incoercible vomiting. On admission, the clinical examination revealed that the condition started about 1 month back with poor general and nutritional condition. Pyloric stenosis was suspected but this hypothesis was rejected based on abdominal ultrasound. Further investigations were done with an abdominal X-ray and an upper gastrointestinal barium study which led to the conclusion of an organo-axial gastric volvulus. The patient died in the course of treatment. Conclusion: Gastric volvulus is an often-misunderstood condition. Upper gastrointestinal barium study remains the gold standard of diagnosis. Its management is surgical.
\end{abstract}

\section{Keywords}

Stomach, Volvulus, Upper Gastrointestinal Barium Study, Surgery

\section{Introduction}

The gastric volvulus is an upper digestive obstruction due to an abnormal rotation of the stomach of more than $180^{\circ}$ [1]. Acute gastric volvulus is a diagnostic and therapeutic emergency. Its incidence is unknown due to the possibility of a chronic form [2]. Its clinical presentation is not very specific [3] and its diagnosis is essentially based on radiological exploration. We report a case of gastric volvulus diagnosed in a child, followed by a review of the literature. 


\section{Observation}

The patient is a 2-year-old boy, referred to the University hospital center of Parakou for incoercible vomiting. He had previously received medical treatment for malaria and acute gastroenteritis. Upon admission to the surgery department, his medical history revealed: symptom onset dating back to about one month with incoercible vomiting later associated with weight loss and fever. Examination of his general condition noted a lethargic, skinny and pale child with a temperature of $37.3^{\circ} \mathrm{C}$, a pulse rate of 104 beats/minute and a respiratory rate of 28 cycles/minute. The values of anthropometric parameters reflected severe acute malnutrition (height to weight Index $<3$ and Brachial Perimeter $=$ $110 \mathrm{~mm}$ ). The abdomen was depressed with no masses. Pyloric stenosis was suspected.

Frontal abdomen X-ray revealed a voluminous air-fluid image in the right hypochondrium pushing the right hemi diaphragm dome upward and displacing the intestines downward (Figure 1). Following barium swallow, we note a discreetly dilated esophagus displaced in the right hemi thorax, an abnormally oblique and highly located stomach in relation to the cardia, intra-thoracic fundus located on the right side of the esophagus and a vertically positioned antrum (Figure 2).

Further biologic investigation showed: ionic disorders with hyponatremia at

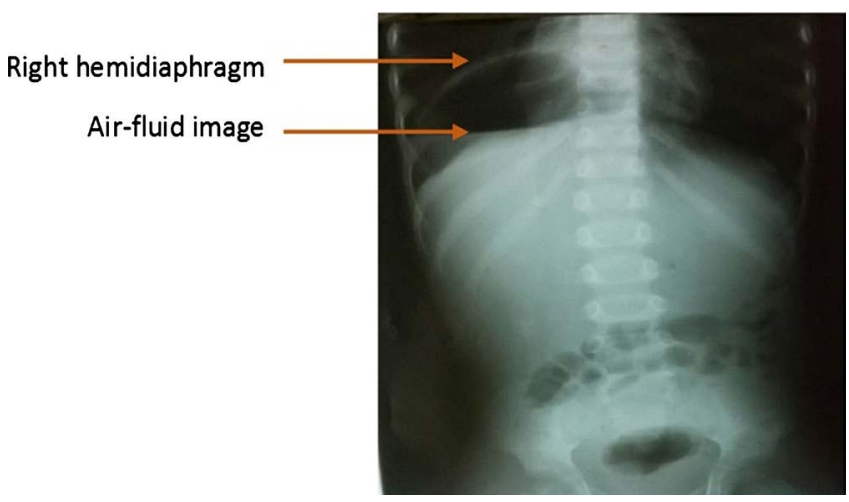

Figure 1. Abdomen X-ray showing an air-fluid image below the right hemidiaphragm.

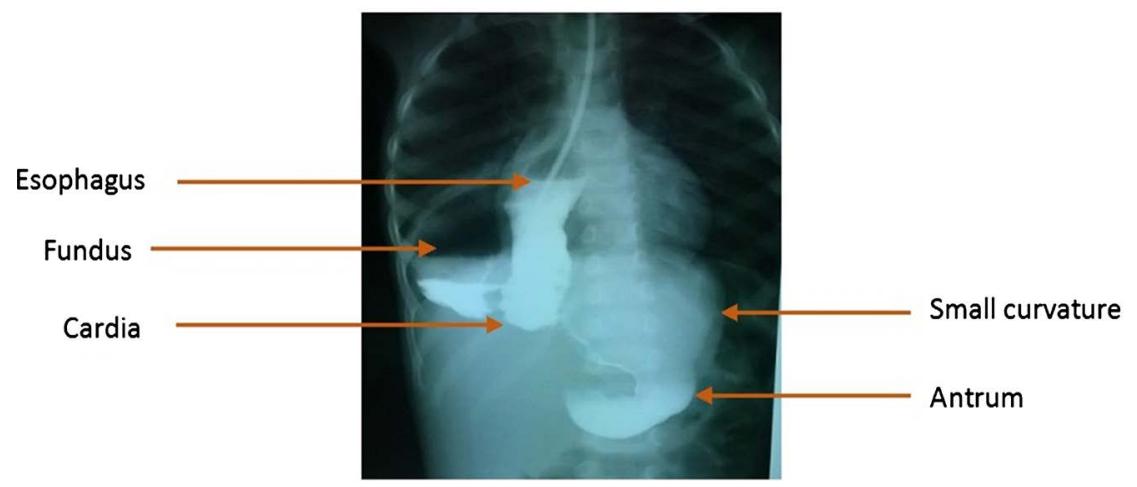

Figure 2. Upper gastrointestinal barium study showing the stomach which had re-volvulized in the organoaxial position. 
$128 \mathrm{mmol} / \mathrm{l}$, hypochloremia at $86.6 \mathrm{mmol} / \mathrm{l}$ and hypokalemia at $2.37 \mathrm{mmol} / \mathrm{l}$, anemia at $7.3 \mathrm{~g} / \mathrm{dl}$, hypoprotidemia at $49.4 \mathrm{~g} / \mathrm{dl}$. Medical resuscitation was initiated to correct the various disorders (nasogastric intubation which brought back blackish liquid, hydro-electrolytic and protein intake). The preoperative check-up was initiated. Unfortunately the patient died during this preoperative resuscitation phase. A detorsion followed by gastropexy were planned associated with a jejunostomy in order to allow the rapid improvement of the nutritional status.

\section{Discussion}

Acute torsion of the stomach is rare because of the stomach's strong fixations by four ligaments: gastrocolic, gastrophrenic, gastrosplenic and gastrohepatic [1]. Gastric volvulus is most often found in the elderly with a peak frequency around the age of 50 [4] but can also affect children [5]. In our hospital, this is probably the first case encountered in a child. There are many etiological factors. In children, a congenital diaphragmatic defect (hiatal hernia or Bochdalek hernia) is an essential factor because negative intra-thoracic pressure as well as pressure from other abdominal organs favors the occurrence of the volvulus. This is not the case in our patient he had no diaphragmatic abnormalities. This was the primitive form, linked according to Grignon, B. and Ksia, A. et al. [1] [6] to a laxity of the gastric ligaments.

Two main anatomical types of torsion exist according to the axis of rotation. The first, called organoaxial, is characterized by the rotation of the stomach around the cardio-pyloric axis, which produces a true volvulus (Figure 3(A))

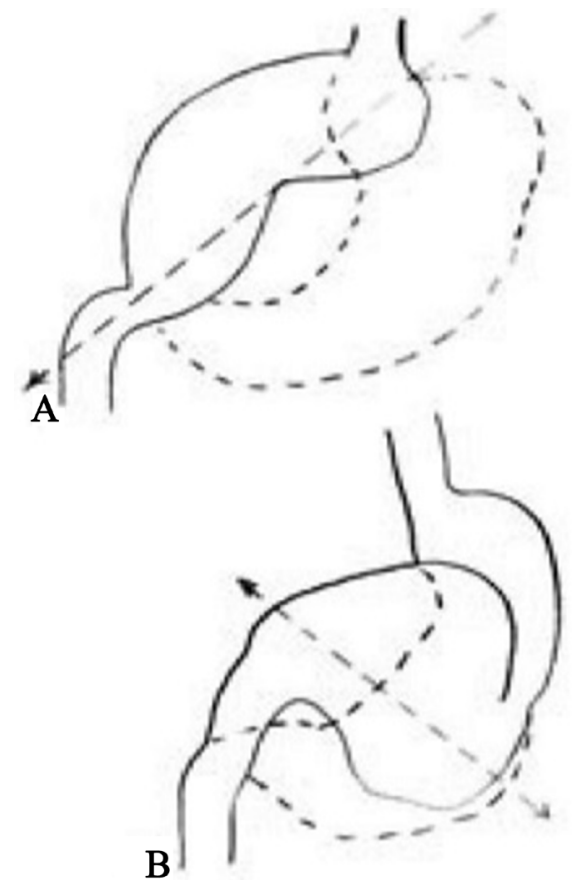

Figure 3. Main anatomical varieties of gastric volvulus [1] (A) Organoaxial variety; (B) Mesentero-axial variety. 
[1]. In the second type, called mesentero-axial volvulus (Figure 3(B)) [1], the stomach rotates around a transverse axis connecting the middle of the greater and lesser curvatures (this axis is perpendicular to the axis of the mesenteric vessels). This second type actually causes more of folding rather than true torsion. A combined type and an unclassified type have also been reported [7]. Depending on the extent of gastric involvement, the volvulus is either partial (involving the antrum) or total. As for the degree of rotation, it is possible to define an incomplete type and a complete type compromising gastric vascularization [8]. Our patient suffered an organoaxial gastric volvulus, probably incomplete, since the symptomatology had been evolving for 1 month.

Borchardt's classic triad (severe epigastric pain, retching without vomiting, difficulty or impossibility to insert gastric tube) is not verified in children. Indeed, in children, the clinical manifestations are not specific and abdominal pain and especially incoercible vomiting [9] have been reported, as was the case in our report. Abdominal X-ray is usually not very contributive [1]. While many authors, including Bang, C. and Krim, A. et al. [2] [10], consider upper gastrointestinal barium study to be the gold standard because of its high sensitivity and specificity for the diagnosis of gastric volvulus, Larricq, J. [8] states that digestive contrast examinations are often difficult to perform. Grignon, B. et al. [1] share this opinion, suggesting that CT scan should currently be the standard if gastric volvulus is suspected.

The treatment of gastric volvulus depends on its clinical presentation. The acute form is treated as a surgical emergency to prevent complications such as perforation or even peritonitis, shock and death [10]. Surgical treatment is often performed by laparotomy because it allows wide access to the abdominal cavity and combines a reduction of the volvulus, management of complications and treatment of the etiology (gastropexy, closure of the diaphragmatic defect) to prevent recurrence. However, Bedioui et al. [4] in a series of 8 cases of volvulus had not performed gastropexy and did not note any recurrence 3 years later. Gastropexy might be optional as postoperative adhesions in case a laparotomy is performed, most often lead to a spontaneous gastropexy [4]. The coelioscopic method in the treatment of acute gastric volvulus, first tested by Koger in 1993, offers the same advantages although around $25 \%$ were converted to a laparoscopy [11]. Mortality in acute gastric volvulus reaches a rate of $42 \%$ to $56 \%$ due to the complications mentioned above [2]. Our patient's might be the result of many factors, such as electrolyte imbalance and severe anemia, added to severe acute malnutrition.

\section{Conclusion}

Gastric volvulus is a rare and often overlooked condition. It can be caused by multiple etiologies. Upper gastrointestinal barium study remains the gold standard of diagnosis. Acute volvulus is an emergency requiring urgent surgical treatment. 


\section{Conflicts of Interest}

The authors declare no conflicts of interest regarding the publication of this paper.

\section{References}

[1] Grignon, B., Sebbag, H., Reibel, N., Zhu, X., Grosdidier, G. and Roland, J. (2004) Diagnostic tomodensitométrique d'un volvulus gastrique idiopathique aigu. Journal de Radiologie, 85, 1070-1073. https://doi.org/10.1016/S0221-0363(04)97722-0

[2] Bang, C. and Susan, D. (2007) Gastric Volvulus. Emergency Medicine Journal, 24, 446-447. https://doi.org/10.1136/emj.2006.041947

[3] El khadir, A., Degrave, N., Roger, J. and Lisambert, B. (2013) Un cas de volvulus aigu de l'estomac chez l'adulte. Hegel, 3, 259-263. https://doi.org/10.4267/2042/51833

[4] Bedioui, H. and Bensafta, Z. (2008) Volvulus gastrique: diagnostic et prise en charge thérapeutique. La Presse Médicale, 37, 67-76.

https://doi.org/10.1016/j.lpm.2007.03.043

[5] Godshall, D., Mossallam, U. and Rosenbaum, R. (1999) Gastric Volvulus: Case Report and Review of Literature. Journal of Emergency Medicine, 17, 837-840. https://doi.org/10.1016/S0736-4679(99)00092-X

[6] Ksia, A., Haggui, B., Mosbahi, S., Maazoun, K., Sahnoun, L., Chahed, J., et al. (2014) A propos de 5 cas de volvulus gastrique chez l'enfant. Archives de Pédiatrie, 21, 1339-1343. https://doi.org/10.1016/j.arcped.2014.09.005

[7] Shivanand, G., Seema, S., Srivastava, D.N., et al. (2003) Gastric Volvulus Acute and Chronic Presentation. Clinical Imaging, 27, 265-268. https://doi.org/10.1016/S0899-7071(02)00549-1

[8] Larricq, J. (1996) Pathologie Gastrique Rare. Encycl Med Chir Paris Appareil digestif, $12 \mathrm{p}$

[9] Mouhsine, A., Anzaoui, J. and Bouchentouf, R. (2013) Le volvulus gastrique idiopathique aigu: à propos d'une nouvelle observation. Pan African Medical Journal, $14,31$.

[10] Krim, A.O., Andronikou, S. and Rubin, G. (2012) Predisposing Factors for Developing Gastric Volvulus and the Role of Imaging. South African Journal of Surgery, 50, 131-133. https://doi.org/10.7196/sajs.1218

[11] Shah, N.N., Mohsin, M., Khursheed, S.Q., Farooq, S.S.A., Buchh, A.A. and Quraishi, A.Q. (2008) Eventration of Diaphragm with Gastric Volvulus: A Case Report. Cases Journal, 1, 404. https://doi.org/10.1186/1757-1626-1-404 